\title{
Alimentação de leitões na creche com rações contendo frutooligosacarídeos
}

\author{
Feeding piglets in the nursey with rations containing fructooligosacharides
}

\author{
Paulo Rogerio Saurin Visentini ${ }^{\mathrm{I}^{*}}$ Dirlei Antonio Berto ${ }^{\mathrm{II}}$ Francisco Stefano Wechsler ${ }^{\mathrm{II}}$ \\ Thais Aparecida Cardoso ${ }^{\text {III }}$ Vanessa de Souza Castro ${ }^{\text {III }}$
}

\section{RESUMO}

O experimento foi conduzido com 210 leitões desmamados, afim de avaliar os efeitos da adição de frutooligosacarídeos (FOS) ou olaquindox nas rações sobre o desempenho dos 21 aos 63 dias de idade. Utilizou-se programa de alimentação por fases (pré-inicial, inicial-I e inicial-II, de zero aos 16, 17 aos 30 e dos 31 aos 42 dias, respectivamente). O delineamento foi de blocos ao acaso, seis tratamentos e sete repetições de cinco leitões cada: T1 - sem adição de FOS; T2 - com 0,1\% de FOS; T3 - com 0,2\% de FOS; T4 - com 0,3\% de FOS; T5 - com 0,5\% de FOS e T6 - sem FOS e 25ppm de olaquindox. A adição de FOS não afetou o consumo e o ganho diário de peso nas diferentes fases estudadas. Contudo, verificou-se melhor desempenho dos leitões que receberam olaquindox comparado à média dos demais tratamentos. Ao contrário do olaquindox, a adição de FOS foi ineficiente em promover melhora no desempenho.

Palavras-chave: oligosacarídeos, prebióticos, promotor de absorção, suínos.

\section{ABSTRACT}

The experiment was performed with 210 weaned pigs to evaluate the effects of fructooligosacharides (FOS) and olaquindox supplementation to the diet on their performance from 21 to 63 days of age. Feed program was pre-starter, starter I and starter II diets, 0 to16, 17 to 30 and 31 to 42 days, respectively. The experimental design was a randomized blocks with six treatments and seven repetitions of five each: T1 without FOS; T2 - with $0.1 \%$ FOS; T3 - with $0.2 \%$ FOS; T4 with $0.3 \%$ FOS; T5 - with $0.5 \%$ FOS and T6 - without FOS and 25 ppm olaquindox. Fructooligosacarides supplementation to the diet did not affect the daily consumption and daily weight gain in any of the different periods tested. However, improved performance was observed in pigs treated with olaquindox in comparison to FOS treated pigs. In conclusion, FOS supplementation was inefficient in improving pigs performance, contrasting with results for aloquindox supplementation.

Key words: growth-promoting, oligosacharides, prebiotics, swine.

\section{INTRODUÇÃO}

O desmame é a etapa do manejo mais traumática para o leitão, pois leva à separação da matriz suína, acomodação em outro grupo social com as conseqüentes brigas para estabelecer a nova hierarquia, brusca mudança na composição da dieta e adaptação aos novos ambiente e manejo. Este fatores são estressantes e determinam a queda no desempenho deste animal. A idade em que o processo de desmame está sendo realizado, associada à imaturidade enzimática do sistema digestório do leitão, determina preocupação adicional quanto aos aspectos nutricionais neste período (SOBESTIANSKY et al., 1998).

A microbiota benéfica auxilia na digestão e absorção de nutrientes, produz vitaminas que serão utilizadas pelo hospedeiro e inibe a proliferação de agentes patogênicos (ROY \& GIBSON, 1998). Em situações estressantes, a microbiota intestinal sofre alterações e a população de bactérias benéficas diminui. Por sua vez, aumentam as patogênicas que geram metabólitos tóxicos ao hospedeiro, causando inflamações na mucosa intestinal, além de estabelecer

IPrograma de Pós-graduação em Zootecnia, Faculdade de Medicina Veterinária e Zootecnia (FMVZ), Universidade Estadual Paulista (UNESP), Botucatu, SP, Brasil. Endereço para correspondência: Rua dos Cravos, 110, Patronato, 97020-200, Santa Maria, RS, Brasil. E-mail: pvisentini@hotmail.com. *Autor para correspondência.

${ }^{I}$ Departamento de Produção Animal, FMVZ, UNESP, Botucatu, SP, Brasil.

${ }^{\text {IIIC } C u r s o ~ d e ~ g r a d u a c ̧ a ̃ o ~ e m ~ Z o o t e c n i a, ~ F M V Z, ~ U N E S P, ~ B o t u c a t u, ~ S P, ~ B r a s i l . ~}$ 
condição propícia ao surgimento de enfermidades. Estas alterações provocam prejuízos imediatos no desempenho animal (SILVA \& NÖRNBERG, 2003).

Para a melhoria no desempenho dos suínos, são usados produtos considerados promotores de absorção, como antibióticos e quimioterápicos. Um grande número de substâncias teve a eficácia comprovada em melhorar a produtividade dos animais ao longo das últimas décadas e o uso como aditivos de rações se generalizou (MENTEN, 2001).

O uso de antimicrobianos nas dietas animais vem sendo, porém, questionado em vários países desde a década de 90. A razão desta discussão está relacionada à possibilidade deles serem tóxicos e ou cancerígenos, comprometendo a saúde humana, quando seus resíduos estiverem presentes em produtos alimentícios de origem animal, além da possibilidade de causar problemas de resistência aos antibióticos (PENZ Jr, 2003). Por este motivo, tornou-se crescente a diminuição ou a proibição do uso dos antibióticos como promotores de crescimento nas rações em vários países (BEST, 1999). No Brasil, o Ministério da Agricultura, Pecuária e Abastecimento (MAPA) tem limitado cada vez mais o uso de alguns antibióticos e antimicrobianos como promotores de absorção para suínos.

A crescente restrição ao uso de drogas como promotores do crescimento animal fez com que surgisse nova geração de produtos, desenvolvidos com o objetivo de auxiliar no equilíbrio benéfico da microbiota do trato gastrintestinal. Entre eles, os prebióticos, ou oligosacarídeos, difundidos como produtos saudáveis disponíveis no mercado (SILVA \& NÖRNBERG, 2003).

Os prebióticos são compostos não digeridos por enzimas, sais e ácidos produzidos pelo organismo animal, mas utilizados, seletivamente, por microrganismos do trato gastrintestinal. Esses compostos podem atuar beneficamente sobre a modulação da microbiota nativa, sobre o sistema imune e sobre a mucosa intestinal, melhorando os processos de digestão e absorção dos nutrientes. A adição de compostos com ação prebiótica às dietas nem sempre corresponde à resposta biológica, o que pode estar relacionado à composição dos ingredientes da dieta, à dosagem adicionada, à adaptação e a seletividade da microbiota ao prebiótico (SILVA \& NÖRNBERG, 2003).

Entre os prebióticos, os frutooligosacarídeos (FOS) são compostos de duas a 10 moléculas de frutose, e podem ser naturais ou sintéticos. Os naturais são derivados de plantas (inulina e seu produto de hidrólise parcial oligofrutose) (MENTEN, 2001). Os sintéticos são obtidos da polimerização direta de alguns dissacarídeos, por meio do fracionamento da parede celular de leveduras ou fermentação de polissacarídeos (MANLEY \& RICHARDS, 1994).

Com a crescente restrição ao uso de drogas veterinárias como promotores do crescimento animal, este trabalho teve como objetivo avaliar os efeitos da adição de frutooligosacarídeos na alimentação de leitões na creche.

\section{MATERIAL E MÉTODOS}

O experimento foi conduzido na unidade experimental de creche localizada na Fazenda Edgardia, pertencente à FMVZ-UNESP, Botucatu, nos meses de fevereiro a março de 2004. Utilizaram-se 210 leitões da linhagem Dalland com peso inicial e final de 5,93 e 21,36kg, respectivamente (21 aos 63 dias de idade), oriundos de granja positiva para micoplasma. O experimento constou de seis tratamentos e sete repetições com cinco leitões cada. O delineamento foi blocos ao acaso, sendo o critério para a formação dos blocos o peso inicial. Os animais foram alojados na sala de creche contendo 42 baias metálicas suspensas, medindo $1,00 \times 1,70 \mathrm{~m}$, equipadas com comedouro tipo cocho, bebedouro tipo chupeta e aquecedor, durante toda a fase inicial. As temperaturas mínimas e máximas no interior da sala foram aferidas diariamente.

A cada unidade experimental foi, aleatoriamente, atribuído um dos seguintes tratamentos: T1, ração sem adição de FOS; T2, ração com adição de 0,1 \% de FOS; T3, ração com adição de 0,2 \% de FOS; T4, ração com adição de 0,3\% de FOS; T5, ração com adição de 0,5\% de FOS e T6, ração sem adição de FOS e adição de 25ppm de olaquindox. O produto utilizado continha concentração de $50 \%$ de FOS.

Os leitões receberam rações fareladas à vontade e foram submetidos a um programa alimentar composto por três dietas, ração pré-inicial nos primeiros 16 dias, ração inicial-I dos 17 aos 30 dias e ração inicialII dos 31 aos 42 dias. Estas foram formuladas para atender no mínimo as exigências nutricionais propostas pelo NRC (1998) para cada fase estudada (Tabela 1).

O ganho de peso foi calculado com base na pesagem dos animais no início do experimento, nos 16 , nos 30 e 42 dias, após período de jejum sólido de 12 horas. O consumo de ração foi calculado baseando-se na ração fornecida diariamente e na pesagem das sobras nos 16, nos 30 e 42 dias.

Os dados de desempenho foram submetidos à análise de variância usando o procedimento GLM do SAS (1998). Os níveis crescentes de 
Tabela 1 - Composição centesimal e níveis nutricionais das rações pré-inicial (0-16 dias), inicial-I (17-30 dias) e inicial-II (31-42 dias).

\begin{tabular}{|c|c|c|c|}
\hline Ingredientes (\%) & Pré-inicial & Inicial I & Inicial II \\
\hline Milho $^{\mathrm{a}}$ & 48,44 & 54,66 & 61,39 \\
\hline Farelo de soja & 18,80 & 22,64 & 27,62 \\
\hline Soro de leite & 8,00 & 4,00 & 0,00 \\
\hline Lactose & 4,50 & 0,00 & 0,00 \\
\hline Proteína isolada de soja & 1,00 & 0,80 & 0,00 \\
\hline Plasma sangüíneo (spray dried) & 4,00 & 2,00 & 0,00 \\
\hline Farelo de glúten de milho-60\% & 2,00 & 2,00 & 2,00 \\
\hline Maltodextrina & 5,00 & 5,00 & 0,00 \\
\hline Sacarose & 3,00 & 4,00 & 4,00 \\
\hline Óleo de soja & 1,00 & 1,20 & 1,55 \\
\hline Calcário calcítico & 0,64 & 0,61 & 0,66 \\
\hline Fosfato bicálcico & 1,95 & 1,91 & 1,70 \\
\hline $\mathrm{NaCl}$ & 0,30 & 0,30 & 0,35 \\
\hline L-Lisina - HCl-78\% & 0,50 & 0,42 & 0,37 \\
\hline DL-Metionina-99\% & 0,11 & 0,07 & 0,02 \\
\hline L-Treonina-98\% & 0,13 & 0,11 & 0,08 \\
\hline L-Triptofano-98,5\% & 0,06 & 0,04 & 0,02 \\
\hline Suplemento vitamínico ${ }^{\text {b }}$ & 0,10 & 0,10 & 0,10 \\
\hline Suplemento mineral ${ }^{\mathrm{C}}$ & 0,10 & 0,10 & 0,10 \\
\hline Óxido de Zinco & 0,33 & 0,00 & 0,00 \\
\hline Cloreto de colina & 0,04 & 0,04 & 0,04 \\
\hline Composição calculada & 100 & 100 & 100 \\
\hline Energia digestível (kcal/kg) & 3435,00 & 3437,00 & 3430,00 \\
\hline Proteína bruta (\%) & 19,50 & 19,00 & 19,00 \\
\hline Lactose (\%) & 14,20 & 7,10 & - \\
\hline Lisina total (\%) & 1,45 & 1,32 & 1,20 \\
\hline Metionina total (\%) & 0,39 & 0,36 & 0,32 \\
\hline Treonina total (\%) & 0,94 & 0,86 & 0,78 \\
\hline Tript ofano total (\%) & 0,26 & 0,24 & 0,22 \\
\hline Сa (\%) & 0,80 & 0,78 & 0,74 \\
\hline P total (\%) & 0,65 & 0,64 & 0,60 \\
\hline
\end{tabular}

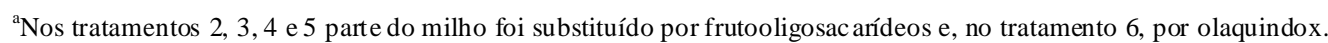

${ }^{\mathrm{b}}$ Fornecendo as seguintes quantidades por quilo de ração: 9.000UI vit. A; 2250UI vit D3; 22,5mg vit. E; 2,25mg vit. K3; 2,03mg vit. B1; $6 \mathrm{mg}$ vit. B2; 3mg vit. B6; 30mcg vit. B12; 0,9mcg ácido fólico; 14,03mg ácido pantotênico; 30mg niacina; 0,12mg biotina.

${ }^{c}$ Fornecendo as seguintes quantidades por quilo de ração: 100mg de Fe; 10mg de Cu; 40mg de Mn; 100mg de Zn; 1mg de Co; 1,5mg de I.

frutooligosacarídeos (tratamentos 1 ao 5) foram analisados por regressão. Um contraste ortogonal foi empregado para comparar cada média do tratamento com olaquindox com a média dos demais tratamentos.

\section{RESULTADOS E DISCUSSÃO}

As médias de temperaturas mínimas e máximas no interior da unidade de creche foram 23,3 e $28,9^{\circ} \mathrm{C}$, respectivamente, durante o período de realização do experimento.

Na tabela 2 são apresentados os resultados de desempenho (consumo diário de ração, ganho diário de peso e conversão alimentar) dos leitões nas fases de zero a 16 dias, zero a 30 dias e zero a 42 dias.
No período experimental, verificaram-se, de maneira generalizada, sinais clínicos de pneumonia enzoótica como espirros e tosse, especialmente a partir dos 35 dias de idade dos leitões. A micoplasmose, além de comprometer o desempenho, segundo SOBESTIANSKY et al. (1999), é uma enfermidade que causa imunossupressão, o que poderia explicar as médias relativamente baixas de ganho de peso e eficiência alimentar dos leitões principalmente nos períodos de zero a 30 e zero a 42 dias de experimento.

A adição de FOS às rações não influenciou o consumo e o ganho de peso dos leitões nos diferentes períodos. Entretanto, a adição de fosfato às rações determinou efeito quadrático sobre a conversão alimentar nos períodos de zero a 30 e de zero a 42 dias,

Ciência Rural, v.38, n.5, ago, 2008. 
Tabela 2 - Médias do consumo diário de ração (CDR), ganho diário de peso (GDP) e conversão alimentar (CA) dos leitões em função dos tratamentos nos períodos de zero a 16,0 a 30 e zero a 42 dias.

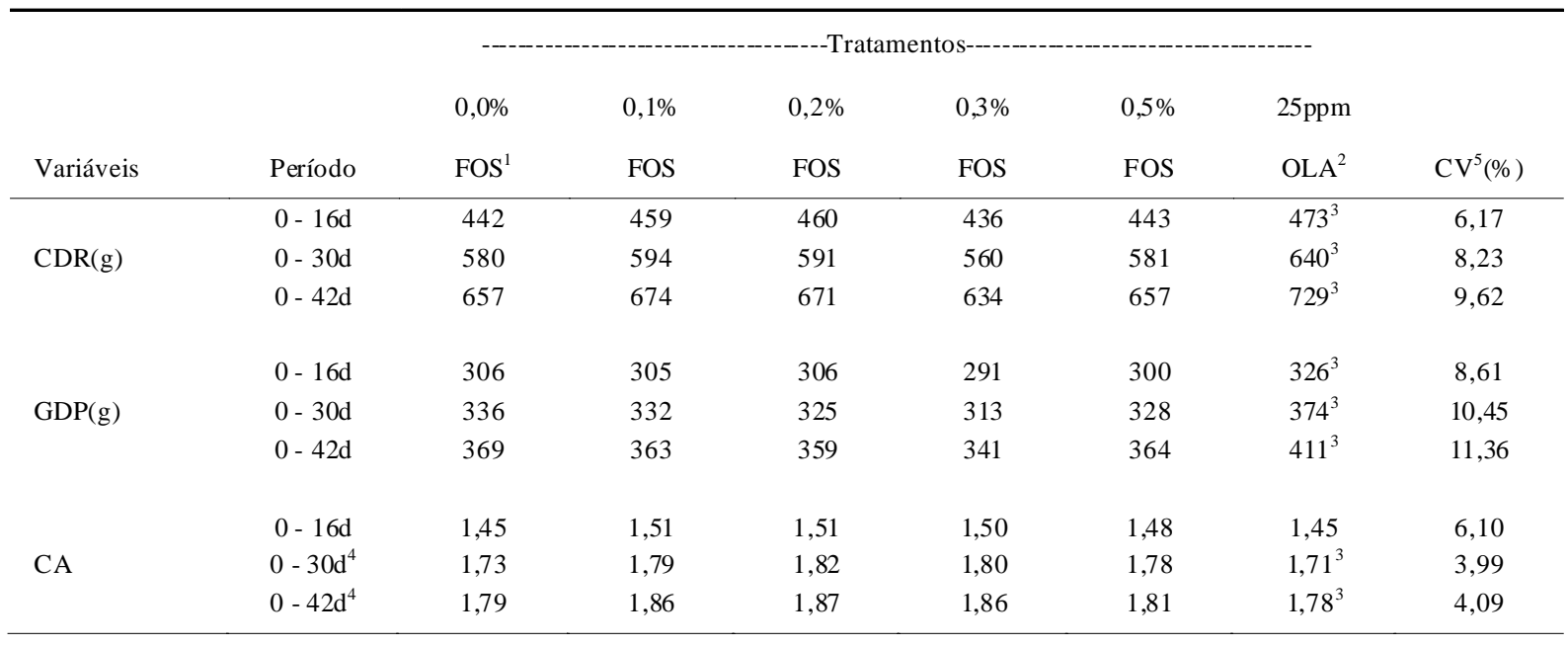

${ }^{1}$ FOS - Frutooligosacarídeos.

${ }^{2}$ OLA - Olaquindox.

${ }^{3}$ Difere da média dos outros tratamentos pelo contraste ortogonal $(P<0,05)$.

${ }^{4}$ Resposta quadrática da adição de frutooligosacarideos $(\mathrm{P}<0,05)$.

${ }^{5} \mathrm{CV}$ - coeficiente de variação.

o que foi de difícil interpretação biológica, considerando a natureza dos tratamentos, e, provavelmente, está relacionada com o surto de pneumonia enzoótica que pode não ter acometido de maneira uniforme os leitões nos diferentes tratamentos.

Os resultados obtidos concordaram parcialmente com os achados por KORNEGAY etal.(1992), FRANTZ et al. (2003), MIKKELSEN et al. (2003), que não observaram diferenças significativas no desempenho de leitões alimentados com FOS quando comparados com os animais do grupo de controle sem promotor.

A depressão temporária no consumo e no ganho diário de peso de leitões desmamados foi verificada por HOUDIJK et al. (1999), porém, o desempenho não foi afetado durante a fase total do experimento. BUDINÕ et al. (2002) também observaram pequena redução no consumo diário de ração, mas verificaram melhora no desempenho dos leitões durante a fase total com a utilização do FOS. Resultados de desempenhos favoráveis com a suplementação com FOS às raç̃oses de leitões foram obtidos por FUKUYASU et al. (1987) e HE et al. (2002).

Os resultados obtidos poderiam ser explicados pelo fato de os ingredientes das rações, como, o farelo de soja, conterem níveis consideráveis de FOS (HENRY \& SAINI, 1989). Outro fator de influência foi o uso de dietas complexas com plasma sangüíneo "spray dried” e derivados lácteos. O plasma sangüíneo "spray dried", possui imunoglobulinas integras que auxiliam o leitão recém-desmamado a manter o equilíbrio da microbiota (KATS et al., 1994; CAIN \& ZIMMERMAN, 1997).

A comparação das médias de desempenho por contraste ortogonal evidenciou melhores resultados das rações contendo olaquindox.

Os resultados positivos com o uso de olaquindox poderiam ser explicados pela ação do mesmo sobre microorganismos gram negativos e gram positivos, principalmente Clostridium spp., Brachyspira hyodysenteriae e anaeróbicos (SOBESTIANSKY \& BARCELLOS, 1998). Apesar do pouco desafio, a presença da pneumonia enzoótica, doença imunossupressora, determinou maior susceptilidade dos leitões a outros microrganismos. Assim, aqueles que receberam olaquindox, provavelemente, estariam mais protegidos, apresentando melhores resultados de desempenho, confirmados por RUSSEL et al. (1998), que trabalharam com FOS e carbadox, produto do mesmo grupo químico do olaquindox (quinoxalinas), e verificaram melhor ganho de peso e eficiência alimentar de leitões, comparados com os animais do grupo controle.

\section{CONCLUSÕES}

A adição de frutooligosacarídeos às rações complexas não favorece o desempenho dos leitões. 


\section{REFERÊNCIAS}

BEST, P. Europa confirma la proibición de antibióticos. Industria Porcina, v.19, n.2, p.5-6, 1999.

BUDINÕ, F.E.L. et al. Desempenho de leitões desmamados alimentados com rações contendo probiótico e/ou prebiótico. In: CONGRESSO LATINO AMERICANO DE SUINOCULTURA, 2002, Foz do Iguaçu. Anais... Foz do Iguaçu, 2002. p.277-278.

CAIN, C.M; ZIMMERMAN, D.R. Effect of spray dried plasma (SDP) on faecal shedding of hemolytic E. coli (HEC) and rotavirus by pigs in a segregated early-weaned (SEW) environment. Journal of Animal Science, v.75, p.61, 1997.

FRANTZ, N.Z. et al. Effects of prebiotic, inulin, and a direct feed microbial on growth performance of weanling pigs, 2003. Capturado em 20 jan. 2005. Online. Disponível na Internet http://oznet.ksu.edu/library/lvstk2/srp920.pdf>.

FUKUYASU, T. et al. Effect of oligosaccharides on growth of piglets and on bacterial flora, putrefactive substances and volatile fatty acids in their feces. Bulletin of Animal Hygiene, v.26, p.15-22, 1987.

HE, G. et al. Evaluation of chicory inulin extracts as feed additive for early-weaned pigs. Journal of Animal Science, v.80, p.393, 2002.

HENRY, R.J.; SAINI, H.S. Characterization of cereal sugars and oligosaccharides. Cereal Chemical, v.66, p.362-365, 1989.

HOUDIJK, J.G.M. et al. Apparent ileal and total-tract nutrient digestion by pigs as affected by dietary nondisgestible oligosaccharides. Journal of Animal Science, v.77, p.148158, 1999.

KATS, L.J. et al. The effect of spray-dried porcine plasma on growth performance in the early-weaned pig. Journal of Animal Science, v.72, p.2075-2081, 1994.

KORNEGAY, E.T. et al. Effectiveness and safety of fructooligosaccharides for pigs. Journal of Animal Science, v.70, p.1-18, 1992.

MANLEY, H.M.; RICHARDS, G.N. Nutritional gains from sucrose caramels, a synopsis of the potential. International Sugar Journal, v.96, p.1144, 1994.
MENTEN, J.F.M. Aditivos alternativos na nutrição de aves: probióticos e prebióticos. In: REUNIÃO ANUAL DA SOCIEDADE BRASILEIRA DE ZOOTECNIA, 38., 2001, Piracicaba. Anais... Piracicaba: SBZ, 2001. p.141-157. CDROM. Nutrição de não ruminantes.

MIKKELSEN, L.L. et al. Effects of dietary oligosaccharides on microbial diversity and fructo-oligosaccharide degrading bacteria in faeces of piglets post-weaning. 2003. Capturado em 20 nov. 2004. Online. Disponível na internet http://www.sciencedirect.com/science.

NATIONAL RESEARCH COUNCIL. Nutrient requeriments of swine. 20.ed. Washington, D.C.: National University, 1998. 189p.

PENZ Jr, A.M. A produção animal brasileira frente às exigências dos mercados importadores atuais e futuros. In: REUNIÃO ANUAL DA SOCIEDADE BRASILEIRA DE ZOOTECNIA, 40., 2003, Santa Maria. Anais... Santa Maria: Sociedade Brasileira de Zootecnia, 2003.

ROY, M.; GIBSON, G.R. Probiotics e prebiotics - microbial in menu. C-H-O Carbohydrates, 1998. Capturado em 20 nov. 2004. Online. Disponível na internet http://www.babelfish. Altavista.com/cgi-bm>.

RUSSELL, T.J. et al. Supplementation of nursey diets with fructooligosaccharide enhances growth performance of the weaned pig, 1998. Capturado em 20 jan. 2005. Online. Disponível na internet http//:asrc.agri.missouri.edu/deptrpt/100104.pdf.

SAS. STATISTICAL ANALISIS SYSTEM. SAS Institute. User's guide: statistics. Cary, 1998. 956p.

SILVA, L.P.; NÖRNBERG, J.L. Prebióticos na nutrição de não ruminantes. Ciência Rural, v.33, n.4, p.983-990, 2003.

SOBESTIANSKY, J.; BARCELLOS, D. Uso de antimicrobianos em suinocultura. Goiânia: Art 3 Impressos Especiais, 1998. 103p.

SOBESTIANSKY, J. et al. Clínica e patologia suína. Goiânia: Art 3 Impressos Especiais, 1999. 464p.

SOBESTIANSKY, J. et al. Suinocultura intensiva. produção, manejo e saúde do rebanho. Brasília: EMBRAPA-CNPSA: Ministério da Agricultura e Abastecimento, 1998. 388p. 